\title{
Framework to Manage Information Security for Malaysian Academic Environment
}

\author{
Zuraini Ismail $^{1}$, Maslin Masrom², Zailani Mohamad Sidek ${ }^{1}$, Dayang Suhana Hamzah ${ }^{1}$ \\ ${ }^{1}$ Advanced Informatics School, University Technology Malaysia, Malaysia \\ ${ }^{2}$ Razak School of Engineering and Advanced Technology, University Technology Malaysia, Malaysia
}

\begin{abstract}
Among the ICT challenges of most organizations including those from the academic sector is securing their information. Apart from technological aspect, Higher Education Institutions (HEIs) also must implement and enforce proper policies, procedures, and standards in compliance with laws and regulations to safeguard and secure its assets. In this study, four renowned Malaysian HEIs were the choosen in answering the research questions. Two modes of data collection were adopted in this study; interview and survey. Five major constructs of information security framework (ISF) unique to HEIs were identified during preliminary investigation. The result provides valuable information on ISF practices in establishing the components of the ISF. A proposed ISF specific for HEIs was designed. Then a survey was conducted to investigate IT personnel perceptions on the existing information security policy practices at the various HEIs. The result of the study contributes to the understanding of the status and HEIs practices of information security in Malaysian academic setting.
\end{abstract}

Keywords: Information Security, Information Security Framework, Standards and Policy, Higher Education Institutions.

\section{Introduction}

The demography within Malaysian Higher Education Institutions (HEIs) took an evolutionary change since the introduction of Information Technology (IT) in the education environment. The significant achievement of IT in Malaysia can be traced from the early nineties after various adjustments of regulatory and commercial policies, both macroeconomic and within IT's converging sectors (Hancock, 2000). In pace with such adaptation, Malaysia's HEIs are increasingly utilizing IT in all aspects of its organizational functions.

Apart from obtaining benefits from the use of IT, HEIs are also faced with various emerging network security threat that is the result of increasingly sophisticated methods of attack and the blending of once distinct types of 
attack into more complex and damaging forms (Garuba, et al., 2008). As concluded by McKissack et al. (2010) a gap was noted in terms of the insufficiency of current "best practices where assurance provides confidence on security threats. The survey on the attacks and security incidents reported by MyCERT, CyberSecurity Malaysia for the first quarter (Q1) 2008 revealed that a total of 10,354 security incidents inclusive of spam incidents were reported (MyCERT, 2008). This represented an increase of $5.59 \%$ incidents rate compared to fourth quarter (Q4) in 2007 with total of 9,486 incidents. The categories of incidents identified are intrusion, hack threat, malicious code, denial of service and spam. Thus, HEI IT departments in particular must balance between enabling a highly collaborative, nonrestrictive environment without discounting confidentiality, integrity, and availability of data and computing resources.

To the best of the researchers' knowledge, empirical research on the enforcement in the context of information security continues to remain an under-investigated research area especially in Malaysian HEIs environment. Hence, this research seeks to answer two research questions, namely

- What are the main components that are considered in the proposed ISF for higher education institutions?

- What are the IT personnel perceptions on the existing Information Security policy practices?

This paper is organized into six sections. This section introduces the study concerned and provides the research questions. Section two portrays the literature review of existing security frameworks. The research methodology is then discussed in section three. Section four narrates the results. The next section explains the survey results. Finally the paper ends with discussion and conclusion.

\section{Literature Review}

This section, firstly defines information security. Secondly, the various information security frameworks are examined and then discuss the four standard framework information security commonly used.

\section{Information Security}

Information security (InfoSec) is the safeguarding of information, which has a recognized value to any organization including HEIs. It includes both business and technology related aspects. The purpose of information security is to preserve the three elements: confidentiality, integrity and availability (Kasmiran, 2008), in addition, authenticity, accountability, non-repudiation and reliability.

As the business dependence on information technology has evolved so too has the imperative and scope of information security. This emergence has been characterized by Von Solms (2006) in term of four waves: technical, management, institutional and governance. The development of security standards and frameworks coincide with these four waves.

AS/NZ ISO/IEC 27002:206 lists the following success factors as critical to information security:

- The creation of a security framework that is consistent with the organizational culture.

- Visible management commitment to security.

- Provision of security awareness, training and education is not only limited to stakeholders but also to all employees and where relevant to contractors and third party with relevant to their job functions. 
- Implementation of a measurement system to evaluate the effectiveness of the security program and provide feedback for improvement of security framework.

\section{Information Security Policy Framework}

Framework is define as an the outline action of the more thorough blueprint, which sets out the model to be followed in the creation of the design, selection and initial and ongoing implementation of all subsequent security control. It is also includes information security policies and procedures, security education training programs, and technological controls (Whitman and Mattord, 2007).

From the Information Security (InfoSec) policy perspective, a framework offers a possible starting point for understanding a security policy's impact to an organization, and is intended to guide organizations in developing, implementing, and maintaining security policy (Kasmiran, 2008). Policy should address both logical and physical security. In addition, privacy and confidentiality, integrity and availability, and legal compliance requirements (Computer Associates International Inc, 2005) also should be included.

A primary objective of InfoSec Policy is to define the user's rights and responsibilities in an organization and the effective InfoSec Policy will helps the users understand what acceptable and responsible behavior is in regards to information resources to ensure the safe environment (Hone and Eloff, 2002).

InfoSec Policy has attained an international awareness and several international standards have been built (Hong et al., 2006). The following section will explain the commonly used standards of Information Security Policy.
Existing Information Security Standards Framework

In this section, we discuss the existing standard information security frameworks such as MyMIS, ISO/IEC 27001, COBIT and COSO. Due to the lack of information security framework specifically addressing higher education institutions, the four established framework (MyMIS, ISO/IEC 27001, COBIT and COSO) provided some guideline in developing the proposed information security framework.

\section{$\underline{\text { MyMIS }}$}

Malaysian Administrative Modernization and Management Planning Unit or MAMPU has introduced a handbook called MyMIS. MyMIS basically provides a standard guideline especially for government sector. It comprises of management safeguards, basic operation, technical operation and legal matters (MAMPU, 2002).

\section{ISO/IEC 27001}

ISO/IEC 27001 is an information security standard published by the International Organization for Standardization (ISO) and the International Electrotechnical Commission (IEC) as ISO/IEC 17799:2005. It was subsequently renumbered ISO/IEC 27001 and entitled as Information Technology - Security Techniques - Codes of Practice for Information Security Management. It is stated that the objective is to serve as a single reference point for identifying the range of controls needed for most situations where information systems are used (IEC 27001, 2005).

Various countries like Australia and New Zealand follows the standard as the basis of regional information security-related standards. ISO/IEC 27001 and its variants provide point description of what should be included as a minimum requirement in information security policy. ISO/IEC 27001 also includes a section exclusively on the 
review and evaluation of an information security policy.

Among the component outlined by ISO/IEC 27001 are security policy, organization of information security, asset management, human resources, physical and environmental security, communication and operation management, access control, information system acquisition, development and maintenance, information security incident management, business continuity management and compliance.

\section{$\underline{\text { COBIT }}$}

The Information Systems Audit and Control Association \& Foundation (ISACAF) developed Control Objectives for Information and related Technology (COBIT) to provide management and business process owners with an IT governance model to help understand and manage the risks associated with IT.

COBIT describes the processes and controls needed for implementing an information security policy, rather than focusing on the document itself. It contains a brief section on the Security and Internal Control Framework Policy, which gives various pointers on writing and maintaining such a document. COBIT consists of four main components namely, plan and organize, acquire and implement, deliver and support, and finally monitor and evaluate.

\section{$\underline{\cos O}$}

Committee of Sponsoring Organizations of the Treadway Commission (COSO) concepts involves organizational internal controls, and is not specific to information security management. However, some aspects of the COSO framework could be adopted for managing security in the enterprise. COSO specially is a business-oriented framework for implementing enterprise risk management (Ritchie and Brindley, 2001).
Based on these known information on existing frameworks, their main components were noted. The next section sets the methodology applied in order to answer the research questions.

\section{Methodology}

In addressing the research questions, two phases of data collection were involved, namely, interview and survey. The interview is to determine the main component of ISF for HEIs. Having completed the interviews, a survey was embarked on in examining the IT personnel perceptions on the existing information security policy practices at respective HEIs.

\section{Interview}

The interview conducted involved four (4) HEIs selected located in the Klang Valley. HEIs chosen are all renowned public universities located in the most populous area of Malaysia's economic pulse. For anonymity and confidentiallity reasons, the selected universities are referred as Alpha, Beta, Chi, and Delta. Alpha is a university aspired from a contemporary global Muslim community. Beta University prides to be one of Malaysia's first and oldest universities. Chi University is the only university that has branch campus in every thirteen states of Malaysia. Delta University is a prestigious HEI set among the top universities in Asia. The university remains to be the main contributor in churning technical expertise. The interviewees comprises of IT-expert staff and personnel in-charge of developing the Information Security framework for each HEI. It was noted that most of the respondents are above 40 years of age; while the number of years in their respective organization and are in the current position recorded as more than five years. This implies that the interviewees are best candidates to provide information on an aggregated unit of analysis in relation to views of information security and its implementation and best practices. Each of 
the interview exercises lasted from 45 minutes to an hour. It was conducted between the months of May to June of 2009.

\section{The Survey Instrument}

The outcome of the interviews contributed towards the design of the survey instrument. The aim of this questionnaire is to investigate IT personnel perceptions on the practices of existing information security policy at HELs. Prior to the actual survey, a pilot study was conducted in order to check the reliability and validity of the instrument constructed. The design of the questionnaire proved to be acceptable. No major alterations were needed.
The questionnaire was divided into six sections. Section one highlights user's profile. Section two captures the risk management in the organization. Section three describes information security policy status. Section four consists of survey on awareness program and training that has been carried out at the organization. Section five defines the access control, followed by compliance concerns in section six.

\section{Results}

Through the interviews, Table 1 summarizes the main components considered by the four HEIs in this research.

Table 1: Components of Main Components Considered by HEIs.

\begin{tabular}{|c|l|c|}
\hline HEI & \multicolumn{1}{|c|}{ Component Considered } & Standard adopted \\
\hline Alpha & $\begin{array}{l}\text { Risk Assessment } \\
\text { Physical and Environmental Security } \\
\text { Access Control } \\
\text { Information Security Incident Management } \\
\text { Compliance }\end{array}$ & COBIT \& ISO 27001 \\
\hline Beta & $\begin{array}{l}\text { Risk Assessment } \\
\text { Security Policy } \\
\text { Organization of Information Security } \\
\text { Asset Management } \\
\text { Human Resource Security } \\
\text { Physical and Environmental Security } \\
\text { Communication and Operation Management } \\
\text { Access Control } \\
\text { Information Systems acquisition, development and maintenance } \\
\text { Information Security Incident Management } \\
\text { Compliance }\end{array}$ & \\
\hline Chi & $\begin{array}{l}\text { Management Safeguards } \\
\text { Basic Operations } \\
\text { Technical Operations }\end{array}$ & ISO 27001 \\
\hline Delta & $\begin{array}{l}\text { Management Safeguards } \\
\text { Basic Operations }\end{array}$ & MyMIS \\
\hline
\end{tabular}

As depicted in Table 1, various components were included by the respective HEIs. Beta University adopted all eleven domain of ISO 27001. Unlike Alpha considered only five incorporated also those from COBIT. MyMIS is the standard adopted by Chi and Delta while Chi includes technical operations. Besides this, it is noteworthy to understand the current status of InfoSec policy practices. 
Table 2: Comparison on the Status of Information Security Policy Practices

\begin{tabular}{|c|c|c|c|}
\hline HLI & ISF & Policies IT & Guidelines IT \\
\hline Alpha & None & Available & Available \\
\hline Beta & None & None & Available \\
\hline Chi & None & None & Available \\
\hline Delta & None & Available & Available \\
\hline
\end{tabular}

From Table 2, it is found that none of the HEI has ISF in placed. However, it is minuted that Alpha and Delta both have IT policies in place in comparison to Beta and Chi. Nevertheless, IT guidelines are in place for all the chosen public HEIs.

Hence, this research has summarized the current InfoSec policy practices. With this and the component considered from Table 1, we come up with a proposed conceptual framework suitable to the Malaysian HEIs environment.

\section{SECURITY ELEMENTS}

\begin{tabular}{|c|}
\hline $\begin{array}{ll} & \text { INFORMATION SECURITY POLICY } \\
- & \text { Administrative } \\
- & \text { Physical environment } \\
- & \text { System based security policy } \\
- & \text { Network security } \\
- & \text { Database security }\end{array}$ \\
\hline \begin{tabular}{ll} 
& \multicolumn{1}{c}{ RISK MANAGEMENT } \\
- & Appropriate resources \\
- & Analysis risk \\
- & Business continuity plan \\
- & Disaster recovery plan \\
- & Risk management plan
\end{tabular} \\
\hline \begin{tabular}{ll} 
& \multicolumn{1}{c}{ ACCESS CONTROL } \\
- & Control privilege management \\
- & Administration procedures \\
- & Network infrastructure \\
- & User responsibilities
\end{tabular} \\
\hline $\begin{array}{l}\text { AWARENESS PROGRAM \& TRAINING } \\
-\quad \text { Frequency of program \& Training } \\
-\quad \text { Awareness on security incidents } \\
\end{array}$ \\
\hline \begin{tabular}{ll} 
& \multicolumn{1}{c}{ COMPLIANCE } \\
- & Management responsibility \\
- & Audit security requirements
\end{tabular} \\
\hline
\end{tabular}

\section{Conceptual Framework}

The ISF constructs identified for HEIs was adopted from ISO 27001, MyMIS and COBIT. With the established guidelines, we developed the conceptual information security framework as illustrated in Figure 1.

Based on the four (4) interviews, five main constructs were identified to be considered in the HEI ISF. They are information security policy, risk management, access control, awareness program and training, and compliance. Figure 1 shows the conceptual components with their constructs considered for the proposed ISF.
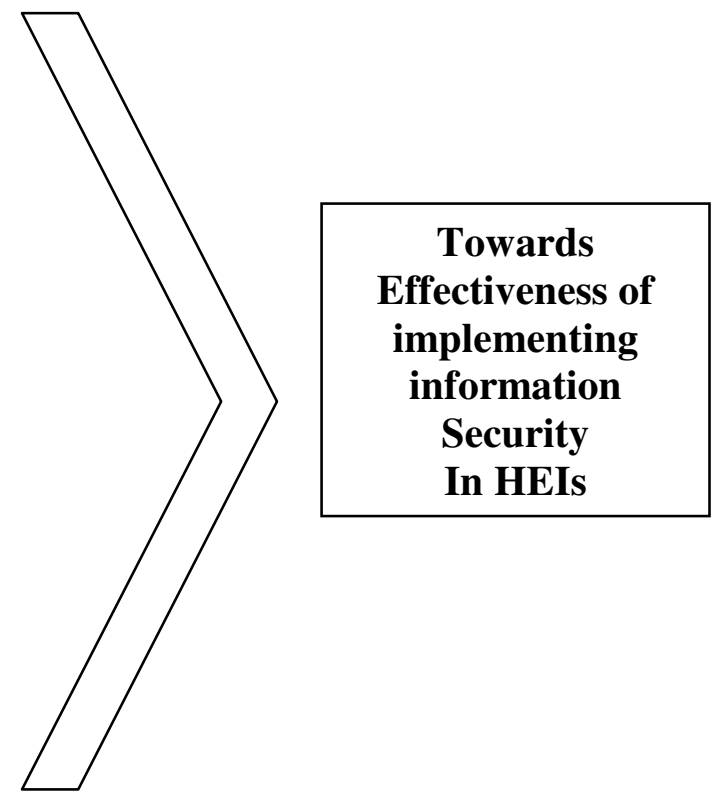

Fig 1. Proposed Conceptual Information Security Framework for HEI 
Five security elements are used to enforce the ISF. The security constructs are briefly described below:

- Information Security Policy - This part explains about security policies. Security policies control address management support, commitment and direction in accomplishing information security goals including information security policy (Carlson, 2001).

- Risk Management - Risk management is the identification and analysis of relevant risks to achievement of the objectives, forming a basis for determining how the risks should be managed (Radack, 2004)

- Access Control - Access control addresses an organization's ability to control access to assets based on business and security requirements including business requirement, user management, user responsibilities, network access control, host access control, application access control, access monitoring and mobile computing (Carlson, 2001).

- Awareness Program \& Training Based on the awareness on the security issues, and is the single most effective means of ensuring information security. The most effective measures depend largely on the behavior of the people affected by those measures. For example, an access control system based on secret password is effective only if people do not share their password (Elliot et al., 1991).

- Compliance - Compliance control addresses an organization ability to remain in compliance with regulatory, statutory and security requirement including legal, technical and system requirements and audits (Carlson, 2001).

Nevertheless, from the four established framework (MyMIS, ISO 27001, COBIT, and COSO) indeed provided beneficial guidelines to the HEIs which in turn form the basis in developing the proposed information security framework depicted in Figure 1.

\section{Survey Results}

The survey was conducted in the month of November and December in 2009. The same four (4) HEIs were involved in the data collection in order to address our second research question. With the assistance of human resource officer of the respective HEI's IT department, we identify the possible respondents for this survey. Two hundred (200) were selected and questionnaires were distributed. Seventy-two (72) questionnaires were returned. This interprets to $36 \%$ response rate. All returned questionnaires were found to be usable for further analysis.

\section{Respondents Profile}

Table 3 portrays the demographic profile of the respondents by gender, age, position in the institution and their years of experience. 
Table 3: Respondents Profile

\begin{tabular}{|c|c|c|c|}
\hline \multicolumn{2}{|c|}{ PROFILE } & FREQUENCY (N) & $\begin{array}{c}\text { PERCENTAGE } \\
(\%)\end{array}$ \\
\hline \multirow{2}{*}{ Gender } & Male & 39 & 54.2 \\
\hline & Female & 33 & 45.8 \\
\hline \multirow{6}{*}{ Age } & 20-25 years old & 18 & 25.0 \\
\hline & 26-30 years old & 16 & 22.2 \\
\hline & 31-35 years old & 16 & 22.2 \\
\hline & $36-40$ years old & 7 & 9.7 \\
\hline & 41-46 years old & 6 & 8.3 \\
\hline & More than 46 years old & 9 & 12.5 \\
\hline \multirow{6}{*}{ Position } & Project Manager & 1 & 1.4 \\
\hline & IT Executive & 14 & 19.4 \\
\hline & IT Management & 7 & 9.7 \\
\hline & Programmer & 36 & 50.0 \\
\hline & System Analyst & 11 & 15.3 \\
\hline & Others & 3 & 4.2 \\
\hline \multirow{4}{*}{$\begin{array}{c}\text { Year of } \\
\text { Experience }\end{array}$} & $1-3$ years & 17 & 23.6 \\
\hline & 4-8 years & 28 & 38.9 \\
\hline & 9-10 years & 5 & 6.9 \\
\hline & More than 10 years & 22 & 30.6 \\
\hline Involved in ISF & Yes & 51 & 70.8 \\
\hline
\end{tabular}

Note: $\mathrm{N}=72$

As depicted in Table 3 above, slightly over than half of respondents $(54.2 \%)$ are male. Nearly half of them $(47.2 \%)$ are below 31 years old and hold the position as programmers. It is noted that more than a quarter of them (38.9\%) have between 4 to 8 years working experience in their organization.

In addition, it was found that nearly threequarters $(70.8 \%)$ of the participants are involved in the development of Information Security Policy in their organization.

\section{Information Security Policy}

This section deals with the status of information security policy available at the respondent's organization. It was found that more than half $(56.9 \%)$ of respondents are aware of the existence of information security policy. Based on these responses, further explanations are provided.

In response, it was indicated that the policy is consistent, easy to understand, and readily available to administrator (27.29\%), faculties (24.47\%), staff $(24.47 \%)$ and student $(23.77 \%)$. A high majority $(95.25 \%)$ of the respondents agreed that the policy is reviewed and approved by the top management. In addition, more than threequarter of the respondents $(92.64 \%)$ rated 'Strongly Agree' and 'Agree' that the policy was reviewed regularly based on significant changes.

Similarly, most respondents (90.18\%) strongly agree that the policy does effectively address the risks identified within their organizations. 
Table 4: Awareness of information security policy

\begin{tabular}{|c|c|c|c|c|c|}
\hline \multirow{3}{*}{ No } & \multirow{3}{*}{ Questions } & \multicolumn{4}{|c|}{ Responses } \\
\hline & & \multicolumn{2}{|c|}{ Yes } & \multicolumn{2}{|c|}{ No } \\
\hline & & $\mathbf{N}$ & $\%$ & $\mathbf{N}$ & $\%$ \\
\hline 1.0 & $\begin{array}{l}\text { Is there any indicator to reflect the adequacy and effectiveness } \\
\text { of the information security policy? }\end{array}$ & 33 & 80.49 & 8 & 19.51 \\
\hline 2.0 & $\begin{array}{l}\text { Does the information security framework cover the following } \\
\text { elements? } \\
\text { a) Risk Management } \\
\text { b) Information Security Policy } \\
\text { c) Access Control } \\
\text { d) Awareness Program \& Training } \\
\text { e) Compliance }\end{array}$ & $\begin{array}{l}29 \\
40 \\
41 \\
36 \\
33\end{array}$ & $\begin{array}{c}70.83 \\
97.72 \\
100 \\
87.87 \\
80.49 \\
\end{array}$ & $\begin{array}{c}12 \\
1\end{array}$ & $\begin{array}{l}5.87 \\
2.28 \\
\\
12.13 \\
19.51 \\
\end{array}$ \\
\hline 3.0 & $\begin{array}{l}\text { The areas that the policy has cover } \\
\text { a) Administrative } \\
\text { b) Physical environment } \\
\text { c) System based security policy } \\
\text { d) Network security } \\
\text { e) Database security }\end{array}$ & $\begin{array}{l}30 \\
31 \\
35 \\
39 \\
33 \\
\end{array}$ & $\begin{array}{l}73.29 \\
75.75 \\
85.41 \\
95.25 \\
80.49\end{array}$ & $\begin{array}{c}11 \\
10 \\
6 \\
2 \\
8\end{array}$ & $\begin{array}{c}26.71 \\
24.25 \\
14.59 \\
4.75 \\
19.51\end{array}$ \\
\hline
\end{tabular}

Note: $\mathrm{N}=41$

Question 1.0 of Table 4, it denotes that more than three-quarter of the respondents $(80.49 \%)$ agreed the policy is effective. The study did reveal that their organization's policy paid attention to administrative (73.29\%), physical environment (75.75\%), system-based security policy (85.41\%), network security $(92.25 \%)$ and database security (80.49\%) area (question 3.0).

There are five (5) constructs listed according to agreement in the information security framework for HEIs. In reference to question 2.0 , the result reported that the respondents totally rated to access control (100\%) as one of the security elements required for the framework. Subsequently, the respondents rated information security policy $(97.72 \%)$, awareness program and training (87.87\%), compliance $(80.49 \%)$ and risk management (70.83\%) accordingly.

\section{Risk Management}

The risk management section seeks to investigate the status of risk management in the organization.
More than half of the respondents $(52.8 \%)$ are aware of the existence of documented risk management policy in their organization. The survey had showed that scenario analysis is the most preferred technique used to identify risk bearing the highest choice (33.58\%) in comparison to the other three techniques. Brainstorming and interview resulted in $27.33 \%$ and $23.45 \%$ respectively. The respondents identified risk management using survey questionnaire is the least used technique (15.64\%).

More than half of respondents $(66.7 \%)$ had agreed that it is very important to have effective risk management in achieving organization's objectives. More than quarter $(27.8 \%)$ indicated that it is somewhat important and a few $(5.6 \%)$ thought that it is not important at all. On the other hand, a majority (95.8\%) of the respondents had rated 'Strongly Agree' and 'Agree' on the issue that effective risk management can improve organization's performance. 
Table 5: Assessment on Risk Management

\begin{tabular}{|c|c|c|c|c|c|}
\hline \multirow{3}{*}{ No } & \multirow{3}{*}{ Questions } & \multicolumn{4}{|c|}{ Responses } \\
\hline & & \multicolumn{2}{|c|}{ Yes } & \multicolumn{2}{|c|}{ No } \\
\hline & & $\mathbf{N}$ & $\%$ & $\mathbf{N}$ & $\%$ \\
\hline 1.0 & $\begin{array}{l}\text { Does your organization is able to allocate appropriate resources } \\
\text { to support current risk management policy and practice? }\end{array}$ & 47 & 65.3 & 25 & 34.7 \\
\hline 2.0 & $\begin{array}{l}\text { Does your organization's response to analyze risks includes: } \\
\text { a) An evaluation of effectiveness of existing controls and risk } \\
\text { management responses. } \\
\text { b) An assessment of the cost and benefits of addressing risk. } \\
\text { c) Prioritizing of risks and selecting those that need active } \\
\text { management. }\end{array}$ & $\begin{array}{l}47 \\
58 \\
57\end{array}$ & $\begin{array}{l}65.3 \\
80.6 \\
79.2\end{array}$ & $\begin{array}{l}25 \\
14 \\
15\end{array}$ & $\begin{array}{l}34.7 \\
19.4 \\
20.8\end{array}$ \\
\hline 3.0 & $\begin{array}{l}\text { Does your organization have the following security measure } \\
\text { documents? } \\
\text { a) Business continuity plan } \\
\text { b) Disaster recovery plan for information technology. } \\
\text { c) Risk management plan. }\end{array}$ & $\begin{array}{l}42 \\
64 \\
52\end{array}$ & $\begin{array}{l}58.3 \\
88.9 \\
72.2\end{array}$ & $\begin{array}{c}30 \\
8 \\
20\end{array}$ & $\begin{array}{l}41.7 \\
11.1 \\
27.8\end{array}$ \\
\hline
\end{tabular}

Note: $\mathrm{N}=72$

From the Table 5 above, question 1.0 reads slightly more than half $(65.3 \%)$ of the respondents clearly defined that their organizations is able to allocate appropriate resource to support current risk. Question 2.0 portrayed that more than half of the respondents agreed that their organization give response to analyze risk including the evaluation of effectiveness (65.3\%), assessment of the cost (80.6\%) and prioritizing of risk $(79.2 \%)$. More than half respondents also stated that their organizations has the following security measure documents which are Business Continuity Plan (58.3\%), Disaster Recovery Plan (88.9\%) and Risk Management Plan $(72.2 \%)$. The result is shown in question 3.0.

\section{Awareness Program \& Training}

In this section, result of status awareness program and training conducted in the organization will be present. Table 6 shows percentage of security awareness program and training conducted for administrator, faculties, staff and students (question 1.0). More than half of the respondents stated the training are frequently held for administrator $(73.6 \%)$ and staff $(75.0 \%)$. As for the faculties $(58.3 \%)$ and student $(40.3 \%)$ seems to record lower agreement on security awareness training.

In examining the duration of awareness program and training, nearly a third of respondents $(30.6 \%)$ stated that it was conducted within six months to one year. About another third (31.9\%) reveals that the program duration is more than one year. It is also reported that slightly over a third of the respondents $(37.5 \%)$ stated that the training is conducted less than six months. It is noted that more than half of the respondents $(52.8 \%)$ stated that their training program was conducted by both internally and other external bodies, with nearly half of respondents $(44.4 \%)$ reported that it was conducted internally. The rest indicated that their training was conducted by other companies. 
Table 6: Determining the awareness program \& training

\begin{tabular}{|c|c|c|c|c|c|}
\hline \multirow{3}{*}{ No } & \multirow{3}{*}{ Questions } & \multicolumn{4}{|c|}{ Answer } \\
\hline & & \multicolumn{2}{|c|}{ Yes } & \multicolumn{2}{|c|}{ No } \\
\hline & & $\mathbf{N}$ & $\%$ & $\mathbf{N}$ & $\%$ \\
\hline 1.0 & $\begin{array}{l}\text { Does your organization conduct any security awareness } \\
\text { program \& training for } \\
\text { a) Administrator } \\
\text { b) Faculties } \\
\text { c) Staff } \\
\text { d) Student }\end{array}$ & $\begin{array}{l}53 \\
42 \\
54 \\
29\end{array}$ & $\begin{array}{l}73.6 \\
58.3 \\
75.0 \\
40.3\end{array}$ & $\begin{array}{l}19 \\
30 \\
18 \\
43 \\
\end{array}$ & $\begin{array}{l}26.4 \\
41.7 \\
25.0 \\
59.7\end{array}$ \\
\hline 2.0 & $\begin{array}{l}\text { Are you aware of your organizations or departments ICT } \\
\text { security policies, procedure and guidelines to protect } \\
\text { information? } \\
\text { a) Security policies } \\
\text { b) Procedure } \\
\text { c) Guidelines }\end{array}$ & $\begin{array}{l}60 \\
56 \\
60 \\
\end{array}$ & $\begin{array}{l}83.3 \\
77.8 \\
83.3 \\
\end{array}$ & $\begin{array}{l}12 \\
16 \\
12 \\
\end{array}$ & $\begin{array}{l}16.7 \\
22.2 \\
16.7\end{array}$ \\
\hline
\end{tabular}

Note: $\mathrm{N}=72$

In the case of computer security incident occurrence, most of respondents (84.7\%) prefer to contact the person in-charge to fix the problem. Very few $(8.3 \%)$ would prefer to self-fix the problem. Very fewer still $(6.9 \%)$ choose to report the problem to administrator via e-mail.

\section{Access Control}

This section will present a result of access control status at the respondents' organizations. The result is shown in Table 7 below.

Table 7 reveals nearly three-quarter $(73.6 \%)$ of the respondents are aware of the existence of written policy for the use network service in their organization (question 1.0).

Most of them are also aware of the existence of access control procedure $(79.2 \%)$ and policies $(75.0 \%)$ as to support the access control policy. This has shown in question 2.0. Based on question 3.0, more than threequarter of the respondents (81.9\%) stated that their organization have control privilege management. The result reported that their organization has protect secured areas by appropriate entry control (95.8\%) (question 4.0), do a check on equipment containing storage media (80.6\%) (question 5.0) and separate the development, test and operational facilities to reduce risk (79.2\%) (question 6.0). Based on question 7.0, respondents agree that both network infrastructure (88.9\%) and administrative procedures $(75.0 \%)$ are maintained and updated.

A high majority of respondents (94.4\%) stated that their organization use a Virtual Private Network (VPN) (question 8.0). More than three-quarter (98.6\%) of the respondents reported that all connection with external network is protected by firewall (question 9.0). According to question 10.0 , more than three-quarter of the respondents $(87.5 \%)$ reported the firewall configurations regularly reviewed and updated. It is further noted, more than threequarter of respondents defined the way they monitor their network traffic by bandwidth statistic $(91.7 \%)$, top protocol bandwidth consumer $(87.5 \%)$ and top IP bandwidth consumer (84.7\%) (question 11.0). 
Table 7: Access control concerns

\begin{tabular}{|c|c|c|c|c|c|}
\hline \multirow{3}{*}{ No } & \multirow{3}{*}{ Questions } & \multicolumn{4}{|c|}{ Answer } \\
\hline & & \multicolumn{2}{|c|}{ Yes } & \multicolumn{2}{|c|}{ No } \\
\hline & & $\mathbf{N}$ & $\%$ & $\mathbf{N}$ & $\%$ \\
\hline 1.0 & $\begin{array}{l}\text { Has management developed and published a written policy on } \\
\text { the use of network services? }\end{array}$ & 53 & 73.6 & 19 & 26.4 \\
\hline 2.0 & $\begin{array}{l}\text { Do access control procedures and policies exist to support the } \\
\text { access control policy? } \\
\text { a) Access control procedures } \\
\text { b) Policies }\end{array}$ & $\begin{array}{l}57 \\
54\end{array}$ & $\begin{array}{l}79.2 \\
75.0\end{array}$ & $\begin{array}{l}15 \\
18\end{array}$ & $\begin{array}{l}20.8 \\
25.0\end{array}$ \\
\hline 3.0 & $\begin{array}{l}\text { Does your organization have control privilege management for } \\
\text { information systems and applications? }\end{array}$ & 59 & 81.9 & 13 & 18.1 \\
\hline 4.0 & $\begin{array}{l}\text { Are secured areas protected by appropriate entry controls to } \\
\text { ensure that only authorized personnel can use the facilities? }\end{array}$ & 69 & 95.8 & 3 & 4.2 \\
\hline 5.0 & $\begin{array}{l}\text { Are all items of equipment containing storage media checked to } \\
\text { ensure that any sensitive data and licensed software has been } \\
\text { removed or securely overwritten prior to disposal? }\end{array}$ & 58 & 80.6 & 14 & 19.4 \\
\hline 6.0 & $\begin{array}{l}\text { Are development, test and operational facilities separated to } \\
\text { reduce the risk of unauthorized access or changes to the } \\
\text { operational system? }\end{array}$ & 57 & 79.2 & 15 & 20.8 \\
\hline 7.0 & $\begin{array}{l}\text { Are the network infrastructure and administration procedures } \\
\text { updated and maintained? } \\
\text { a) Network infrastructure } \\
\text { b) Administration procedures }\end{array}$ & $\begin{array}{l}64 \\
54\end{array}$ & $\begin{array}{l}88.9 \\
75.0\end{array}$ & $\begin{array}{c}8 \\
18\end{array}$ & $\begin{array}{l}11.1 \\
25.0\end{array}$ \\
\hline 8.0 & Does your organization use a Virtual Private Network (VPN)? & 68 & 94.4 & 4 & 5.6 \\
\hline 9.0 & $\begin{array}{l}\text { Are all connections with external network protected by } \\
\text { firewall? }\end{array}$ & 71 & 98.6 & 1 & 1.4 \\
\hline 10.0 & $\begin{array}{l}\text { Are the firewall configurations regularly reviewed and } \\
\text { updated? }\end{array}$ & 63 & 87.5 & 9 & 12.5 \\
\hline 11.0 & $\begin{array}{l}\text { How do you monitor your network traffic? } \\
\text { a) Bandwidth statistic } \\
\text { b) Top protocol bandwidth consumers } \\
\text { c) Top IP bandwidth consumers }\end{array}$ & $\begin{array}{l}66 \\
63 \\
61\end{array}$ & $\begin{array}{l}91.7 \\
87.5 \\
84.7\end{array}$ & $\begin{array}{c}6 \\
9 \\
11\end{array}$ & $\begin{array}{c}8.3 \\
12.5 \\
15.3\end{array}$ \\
\hline
\end{tabular}

Note: $\mathrm{N}=72$ 


\section{Compliance}

Compliance section seeks to examine the status of compliance in the organization. The result is presented in Table 8.

Table 8: Assessment on Compliance

\begin{tabular}{|c|c|c|c|c|c|}
\hline \multirow{3}{*}{ No } & \multirow{3}{*}{ Questions } & \multicolumn{4}{|c|}{ Answer } \\
\hline & & \multicolumn{2}{|c|}{ Yes } & \multicolumn{2}{|c|}{ No } \\
\hline & & $\mathbf{N}$ & $\%$ & $\mathbf{N}$ & $\%$ \\
\hline 1.0 & $\begin{array}{l}\text { Is there a person or committee that has information security as } \\
\text { their primary duty? }\end{array}$ & 62 & 86.1 & 10 & 13.9 \\
\hline 2.0 & $\begin{array}{l}\text { Does your information security policy have the authority it } \\
\text { needs to manage and ensure compliance with the information } \\
\text { security policy? }\end{array}$ & 56 & 77.8 & 16 & 22.2 \\
\hline 3.0 & $\begin{array}{l}\text { Is someone in the information security policy responsible for } \\
\text { liaising with units to identify any new security requirements? }\end{array}$ & 63 & 87.5 & 9 & 12.5 \\
\hline 4.0 & $\begin{array}{l}\text { Does the information security policy actively engage with other } \\
\text { units (human resources, student affairs, faculty and library) to } \\
\text { develop and enforce compliance with information security } \\
\text { policies and practices? }\end{array}$ & 52 & 72.2 & 20 & 27.8 \\
\hline 5.0 & $\begin{array}{l}\text { Does the information security department report regularly to } \\
\text { the governing board on the compliance and the effectiveness of } \\
\text { the information security program and policies? }\end{array}$ & 47 & 65.3 & 25 & 34.7 \\
\hline 6.0 & $\begin{array}{l}\text { Are there specific training programs in place to comply with the } \\
\text { information security and standards with the goal of ensuring the } \\
\text { security of the information systems that support the operations } \\
\text { and assets under control? }\end{array}$ & 45 & 62.5 & 27 & 37.5 \\
\hline
\end{tabular}

Note: $\mathrm{N}=72$

Based on question 1.0 in the table above, more than three-quarter of respondents $(86.1 \%)$ indicate that there is a person or committee in-charge in securing their organization's information. In question 3.0, slightly more than three-quarter $(77.8 \%)$ of the respondents stated that there is also a person in-charge to liaise with other units to identify any new security requirements to the policy.

Slightly more than three-quarter of respondents (77.8\%) agreed that their organizations' information security policy has the authority to ensure compliance with the policy (question 2.0). Still, a majority $(87.5 \%)$ of the respondents agreed that the policy is actively engage with other units to enforce compliance with information security policy and practices (question 4.0).

As to ensure the effectiveness and compliance of information security program and policies, two-third of the respondents $(65.3 \%)$ indicated that the information security department reports regularly to the governing board (question 5.0). Furthermore, result of question 6.0 showed that more than half of the respondents $(62.5 \%)$ agreed that there are specific training programs to comply the policy and standards are necessary. 


\section{Discussion and Conclusion}

This study has successfully answered both the research questions. Firstly, the main constructs of HEIs ISF were determined through interviews. Secondly, based on the IT personal responses through a survey, it establishes their perceptions on the existing information security policy practices.

Through the interviews, it revealed that largely all the established governmentsupported HEIs have some form of IT policies in place. Various establish information security standards were found to form the basis of their efforts towards the development of their very own policy.

This research further discovers that information security policy, risk management, access control, awareness program and training, and compliance are the major components or elements that fix upon the suggested framework for HEIs. These components are in line with the objective of developing the framework which was to apply and cover all hardware, software, data, information, network, personal computing devices, support personnel, and users within HEIs from intrusion, interception, interruption and denial of services.

Through the survey, generally, the respondents who largely were involved in the development of their organization's InfoSec policy perceived the importance of each component of the proposed framework. It was found that using a scenario analysis as a technique to identify risk is found to be more effective since the technique is designed to allow improved the decisionmaking. It considers the outcomes and their implications. In order to have a good risk management policy, organization also must be able to allocate an appropriate resource to support the existing risk management policy. The risk analysis should further emphasize on the assessment of the cost and benefits of addressing risk, similarly prioritizing of risks and its impact and likelihood besides selecting those that need active management and evaluation on the effectiveness of existing controls and risk management responses. Furthermore, most of the organizations have realized that having the disaster recovery plan, risk management plan, and business continuity plan are important in order to protect their organizations data and IT infrastructure in the event of the disruptive situations. This research also found that having an effective risk management can improves organizations' performance and simultaneously, it also helps towards achieving the organizations' objectives.

This study does disclose top management concerns on the importance of adequate information security policy in the organizations. This is indicated by periodically reviewing and updating the policy based on significant changes due in relation to the risk identified by the organizations. Thus, the policy is consistently and readily made available for compliance by the administrator, faculties, staff, students and third party. Accordingly, the findings indicated the effectiveness of the policy the organizations have addressed all the five security constructs identified in the ISF. Access control is found to be the most important security element. Additionally, policy also plays an important role in explaining to staff and students of their responsibility in the protection of the information resources, while stressing the importance of having secured information.

Awareness and compliance is the success key to the policy as implementation will take place after the policy had been endorsed. It was showed that the awareness training has been conducted to administrator and staff in the organization more frequent than for faculties and the students. As the students form the majority of the campus population does it remains imperative to suggest more awareness program towards information security exposure. However, the study showed no bearing on the duration of the 
awareness program and training in relationship to awareness acceptance specifically.

This study also indicated that HEIs appoints specific person in-charge or committee set up in addressing ISF and policy concerns. In furtherance of ensuring the compliance enforcement, information security policy department is actively in cooperation with other units of the organization and regular meetings and scheduled reporting are practiced.

Hence, this effort would provide some clarification and insights into how ISF is depicted in the academic setting. Further work is obviously necessary to look into the details of the framework. Amongst others, matters pertaining to third party, asset management, equipment security, communications, systems acceptance, cryptography and incident management. Thus, this research serves as an expansion of security and assurance in operational areas literature in the area of ISF engagements.

Despite the study's limitations, we believe that our work makes significant contributions to practice and research.

\section{Managerial perspective}

a) It provides as an indicator to the status of ISF implementation from IT personnel perspective.

b) It identified the various standard adopted by HEI or the lack of it.

c) HEIs can enjoy significant benefits from making right choices in terms of construct that are relevant or set a priority- level to its ICT-related activities.

d) Serves as preparatory guidelines for future planning and improvements to HEIs ISF. e) Better understanding of critical ISF construct to ensure successful enforcement of information security.

\section{Theoretical Contribution}

a) Clarification and rearrangement of the available constructs: information security policy, risk management, access control, awareness program and training, and compliance are delineated in the proposed ISF model

b) Identification of new constructs whereby the involvement of top management plays a significant role in sustaining a robust and effective. Notably, adequate implementation and improvement of the ISF hinges on management's commitment.

In a nutshell, this study forms a basis in understanding the status and its practices of information security in Malaysian academic setting. This will further fulfill the HEIs information security needs towards a more dynamic yet sustaining a secured academic environment.

\section{Acknowledgement}

This research is funded by e-Science grant vote number 79317 awarded by the Ministry of Science and Technology Innovation (MOSTI) of Malaysia. Our sincere thanks go to Malaysia's Ministry of Higher Education (MOHE), and the cooperation of participating universities.

\section{References}

AS/NZ ISO/IEC 27002:2006 (2006), 'Information Technology - Security Techniques - Code of Practice for Information Security Management,' $A S / N Z$ ISO/IEC 27002.

Computer Associates International, Inc. (2005). 'Best Practices: Security 
Management.' White Paper published in Partnership Inc.

Elliot, R., Young, O.M., Collins, D.V., Frawley, D. and Temares, L.M. (1991), 'Information Security In Higher Education,' Cause, 1-35.

Garuba, M., Liu, C. and Washington, N. (2008). 'A Comparative Analysis of Anti-Malware Software, Patch Management, and HostBased Firewalls in Preventing Malware Infections on Client Computers' Proceedings of the Fifth International Conference on Information Technology: New Generations, IEEE Computer Society, Washington, 628632.

Hancock, B. (2000), 'New York Times Fired Employees for Violating Internal E-mail Policies,' Computer Fraud and Security, 12, 20.

Hone. K. and Eloff. J.H.P. (2002), 'What Makes An Effective Information Security Policy?' Network Security, 6, 14-16.

Hong, K.-S., Chi Y.-P., Chao, R. L., and Tang J. H. (2006), 'An Empirical Study of Information Security Policy on Information Security Elevation in Taiwan,' Information Management \& Computer Security. 14 (2), 104-115.

Kasmiran, J., (2008), 'The Security Factor In The Information Technology', [Online], [Retrieved February 14, 2009], http://pkukmweb.ukm.my/pkukm/content/ view/84/94/

MAMPU --- Malaysian Administrative Modernization and Management Planning Unit, (2002), MyMIS - Malaysian Public Sector Management of Information \& Communication Technology Security Handbook, Putra Jaya.

McKossack, J., Hooper, V. and Hope, B. (2010), 'An Orgdel for Information security Assessment,' Proceedings of the International Conference on Information Management and Evaluation(ICIME 2010), ISBN: 978-1-
906638-56-6, 25-26 March2010,Reading, England, 218-227.

[Online] [Retrieved January 22, 2009] http://en.wikipedia.org/wiki/ISO/IEC 2700 $\underline{1}$

[Online] [Retrieved February 5, 2009] http://www.mycert.org.my/en/services/adv isories/mycert/2008/main/detail/579/inde x.html

Radack, S. (2004) 'Risk management framework: Helping organizations implement effective information security program,' INS Whitepaper, Santa Clara, INS.

Ritchie, B. and Brindley, C. (2001), "The information-risk conundrum,' Marketing Intelligence and Planning, 19( 1), 29-37.

Carlson, T. (2001), "Information Security Management: Understanding ISO 17799", INS Whitepaper, Santa Clara, INS.

Von Solms, B.,(2006), 'Information Security The Fourth Wave,' Computer and Security, 25, 165-168.

Whitman, E.M. and Mattord, J.H. (2007), 'Management of Information Security,' Thomson Course Technology, Boston. 